\title{
Paraspinal soft tissue masses in a patient with a metabolic bone disease
}

\author{
Aishwarya Gulati $^{1} \cdot$ Achala Donuru $^{1} \cdot$ Rashmi Balasubramanya $^{1}$ - Maansi Parekh ${ }^{1}$ \\ Published online: 10 July 2020 \\ (C) ISS 2020
}

\begin{abstract}
A 48-year-old female with a known metabolic bone disease presented with cough, shortness of breath and worsening fatigue. Labs revealed anemia and thrombocytopenia. What is the relationship between the lab abnormalities and imaging findings in this patient?
\end{abstract}

\section{Compliance with ethical standards}

Disclosures None.

Informed consent Informed consent and IRB are not mandated for single patient case report as per our institution and hence were not obtained.

Publisher's note Springer Nature remains neutral with regard to jurisdictional claims in published maps and institutional affiliations.

The diagnosis can be found at doi: 10.1007/s00256-020-03537-2

Maansi Parekh

maansi.parekh@jefferson.edu

1 Department of Radiology, Thomas Jefferson University Hospital, Philadelphia PA USA 

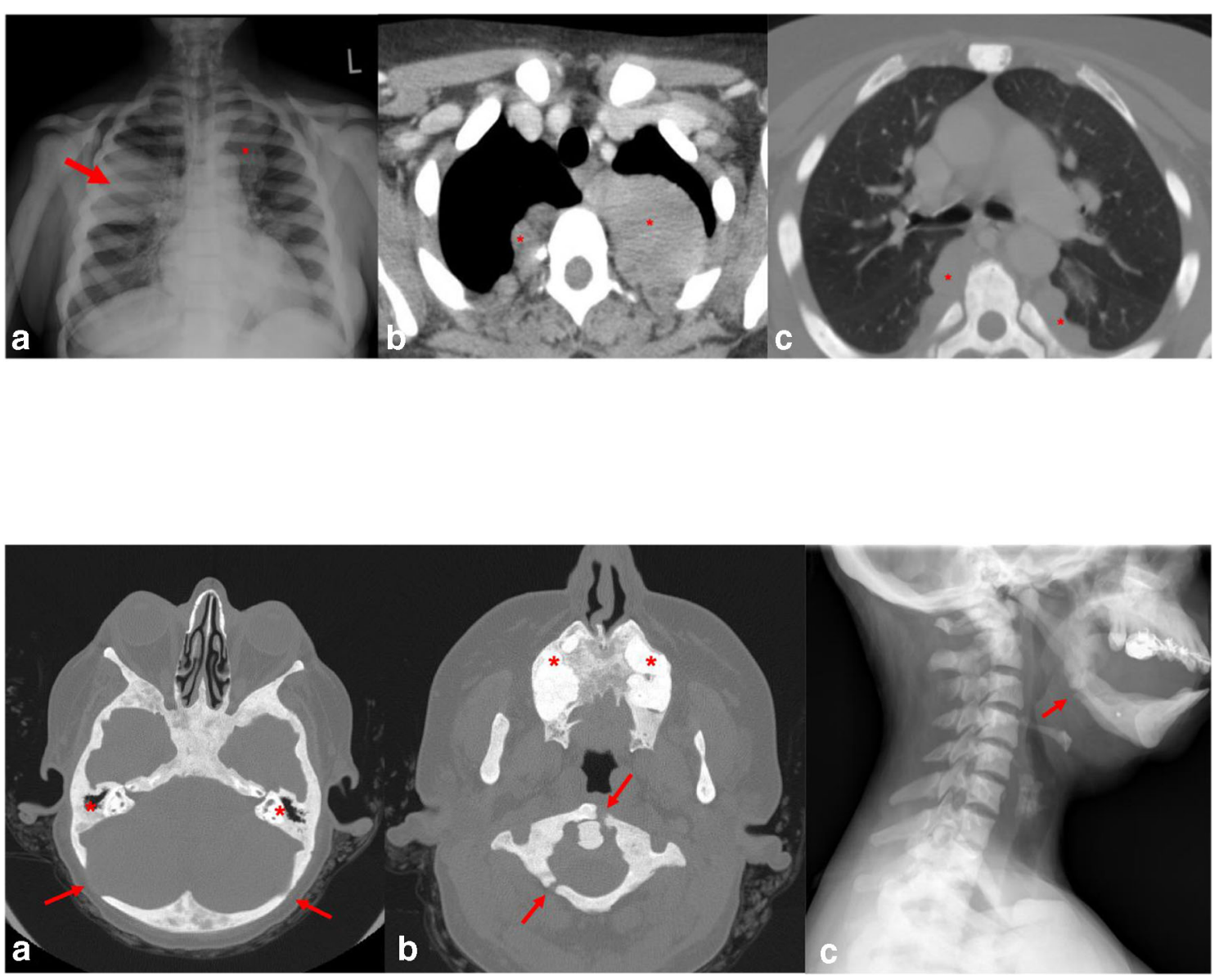